\title{
Qual projeto à esquerda para o Brasil?
}

\author{
What leftist project is there for Brazil?
}

Pedro Paulo Zahluth Bastos'

Em fases históricas de ofensiva da direita, não é incomum o encurtamento das aspirações de parcelas significativas da esquerda a ponto de se preocuparem apenas com a administração da sobrevivência em tempos difíceis, abandonando até mesmo a reflexão sobre horizontes estratégicos, e tanto mais a luta efetiva por eles.

A conjuntura atual é marcada pelo avanço rápido de contrarreformas neoliberais, mas também por sua total impopularidade. Isso coloca uma oportunidade para as esquerdas: se voltarem a pensar grande, parece haver receptividade popular para recriar amplo apoio social para uma estratégia nacional à esquerda. É para tal tarefa que este documento levanta alguns pontos para reflexão.

\section{As condições históricas para um projeto à esquerda foram ou podem ser criadas?}

É evidente que mais importante do que pensar o mundo é transformá-lo, mas não conheço quem o tenha transformado politicamente sem o pensar. Para ser capaz de mudar a realidade, é preciso identificar as condições viabilizadoras, mas também é preciso mobilizar as forças sociais para aproveitar as condições e superá-las. Para isso, é fundamental ter uma visão de onde se quer chegar, ou melhor, construir pelo debate um programa que indique aonde e como chegar.

Sem visão do futuro, que menos que utópica é esperançosa (não necessariamente otimista), não há mobilização ampla: o projeto anima a prática de grandes grupos sociais. A mobilização passa por circular a informação e criar pílulas de agitação política, e é o projeto que fornece os temas da prática mobilizadora e transformadora.

A condição básica para viabilizar um projeto de esquerda, evidentemente, é vencer eleições, mas não apenas. É vencê-las com um mandato que inspire amplo apoio popular e pressione o sistema político, de baixo para cima, para executá-lo. Isso pode não ser alcançado nas eleições de 2018, mas ninguém disse que a batalha será rápida e fácil.

De todo modo, o momento atual, um ano após a aceitação do processo de impeachment no

1 Universidade Estadual de Campinas (Unicamp) Instituto de Economia e Centro de Estudos de Conjuntura e Política Econômica (Cecon) Campinas (SP), Brasil. ppzbastos@gmail.com Senado, já é muito melhor do que maio de 2016. Os riscos são maiores, pois o bloco de poder que controla o governo Temer já aprovou a Lei do Teto do Gasto Público por 20 anos e está prestes a aprovar reformas trabalhista e previdenciária amplas. No entanto, enquanto a resistência em relação ao teto do gasto foi limitada, a resistência contra as reformas constitucionais já provocou talvez a maior greve geral da história brasileira, no último 28 de abril. 
Se houver eleição em 2018, a conjuntura já é muito diferente de 2015 ou de 2016: o isolamento da esquerda acabou, mas o isolamento popular do governo é evidente. Este se sustenta na grande mídia e no grande capital, mas a imensa maioria da população já sabe a quem servem as reformas da previdência e trabalhista. Com um movimento político amplo de conscientização e mobilização, a população pode apoiar sua reversão, inclusive nas eleições proporcionais de 2018.

Ou seja, o fato de que o projeto neoliberal sustentado pela grande mídia e pelo grande capital estão divorciados da população abre espaço para um bloco alternativo que dispute a narrativa e crie apoios para um conjunto de reformas à esquerda. A esperança não é irreal, pois quatro eleições presidenciais já foram vencidas a despeito da oposição midiática. A oportunidade para as eleições proporcionais só será aproveitada, contudo, se o trabalho de base e a disputa pela narrativa que anima corações e mentes avançar em torno a um programa alternativo ao neoliberalismo.

Ademais, o monopólio da acusação da corrupção acabou. Depois das delações da Odebrecht, da OAS e da JBS, o problema da corrupção ficou menos personalizado e mais como de fato é: um atributo estrutural do sistema político (que muitos políticos tradicionais não querem mudar). Não se trata de silenciar cinicamente sobre a questão, mas de enfrentar seus motivos estruturais e atacar a direita pelo fato de que não pretende abordar as estruturas que explicam a corrupção, e sim culpar hipocritamente alguns de seus adversários à esquerda cooptados pelo sistema de compra de votos, decisões e contratos públicos pelos mais ricos, que sempre alimentaram os partidos de direita.

Além da impopularidade da agenda de reformas neoliberais, o apoio potencial a uma alternativa se alimenta do fato de que fracassou a estratégia de recuperação da economia proposta pelo governo Temer. A estratégia política dos golpistas era paralisar o legado institucional e programático construído a partir da Constituição de 1988 e retomado no governo Lula, torcendo para que o povo o esquecesse até 2018 à medida que a economia se recuperasse depois do impeachment.

Para isso, o governo Temer contava com a retomada da confiança empresarial e com uma mudança importante da política fiscal em 2016. Em um cenário de queda de receitas tributárias, é importante que a meta de deficit primário aumente para evitar que o governo seja forçado a cortar gastos enquanto a arrecadação despenca. Caso contrário, o corte do gasto público reforça o círculo vicioso de queda de receitas públicas e privadas.

É verdade que, em 2016, o governo Temer aumentou a meta de deficit para $\mathrm{R} \$ 170,5 \mathrm{bi}$, para permitir maiores gastos mesmo que a arrecadação tributária continuasse despencando. Com isso, o gasto público real aumentou 5\% em 2016 (descontando pagamento de pedaladas). Com a retomada da confiança empresarial, o governo considerava que isso seria suficiente para assegurar a recuperação e a retomada da arrecadação fiscal.

O problema é que o aumento da despesa pública estimulou pouco a economia porque contou muito com o chamado 'keynesianismo fisiológico', ou seja, concessões para interesses poderosos de camadas do aparato judicial-policial, emendas parlamentares e renúncias de receita de concessionários privados de serviços públicos, enquanto o investimento público continuou despencando. Assim, nem a 'fada da confiança' nem o 'keynesianismo fisiológico' fizeram milagres, e a economia até acelerou sua contração nos dois trimestres depois do impeachment, em vista do multiplicador do desemprego e das elevadas taxas de juros.

O efeito político disso é aumentar a nostalgia da população perante o legado do lulismo. É claro que esse legado precisa de revisões, mas como envolvia direitos sociais materializados no gasto público, como o Minha Casa, Minha Vida e o Bolsa Família, sua própria paralisia deliberada tem boa 
responsabilidade pelo aprofundamento da recessão. Logo, sua retomada é o caminho óbvio para a recuperação, com benefícios econômicos e políticos rápidos.

Por outro lado, ter usado a rigidez da meta fiscal anual como pretexto do impeachment e ter anunciado seu cumprimento rígido como condição da credibilidade deixa o governo Temer, agora, preso a seu feitiço. A emenda constitucional do Teto do Gasto só vai ter efeitos em 2018, pois a rápida desinflação em 2017 ainda permite, em tese, o aumento do gasto público real em relação a 2016.

No entanto, o baixo desempenho da arrecadação tributária já exige contingenciamento bimestral do orçamento público como o anunciado no final de março: 42,1 bilhões em cortes, além da reversão das desonerações da folha de pagamento salarial que foi vetada ao governo Dilma. Mantida a meta de deficit de 2017 (R\$ 139 bilhões), o contingenciamento anunciado já determina uma queda do gasto público real em 2017, como se a emenda do teto já valesse.

O que é óbvio é que uma recuperação firme passa inevitavelmente por liberar o deficit público por um tempo. O gasto público não pode cair acompanhando a arrecadação tributária, pois sua contração determina queda das receitas privadas e até mesmo a falência de empresas privadas. Daí a arrecadação tributária cai por causa da queda do gasto privado, e só o deficit público pode interromper o círculo vicioso.

Se a economia se recuperar lentamente a despeito de novos contingenciamentos em 2017, a emenda do teto do gasto público pode jogá-la de novo para baixo em 2018. A recuperação, portanto, exige reverter a emenda constitucional do teto do gasto e criar um novo regime fiscal que desamarre o investimento público e iniciativas anticíclicas, quando necessárias. Isso é condição indispensável para a retomada do desenvolvimento e sua sustentação no tempo.

Em uma economia com volume enorme de recursos ociosos, as taxas de juros reais podem cair sem risco para a inflação, barateando o financiamento da dívida pública. Como se sabe, são os juros da dívida, e não os resultados primários, que determinam a aceleração do endividamento recente. A queda dos juros também abre espaço para uma desvalorização cambial gradual, necessária para conferir competitividade para alguns ramos industriais. Enfatizo o adjetivo 'gradual' para caracterizar a desvalorização cambial, pois uma megadesvalorização, como no final de 2014 e início de 2015, desorganiza expectativas, encarece passivos externos, aumenta a preferência pela liquidez e a retração de investimentos de longo prazo muito antes de ter os efeitos positivos desejados pelos que a defendem. De todo modo, a armadilha dos juros altos e do câmbio baixo não foi desarmada desde 1992, e é essencial que seja para sustentar um novo ciclo de desenvolvimento com redistribuição de renda.

\section{A crítica neoliberal do ativismo estatal e do gasto social}

Reagir ao desmonte exige disputar a narrativa a respeito do impacto econômico do gasto social. Sem qualquer base empírica e com uma base teórica equivocada, os reformistas neoliberais alegam que a economia não cresceu como imaginavam depois do ajuste fiscal de 2015 porque seria necessário aprofundar os cortes e desmontar o capítulo social da Constituição Federal. Ou seja, se a dose do remédio não trouxe o efeito desejado, ao invés de abandonar o tratamento, seria necessário aumentar a dose cavalarmente.

$\mathrm{O}$ risco é que o paciente morra de overdose, pois o diagnóstico é completamente errado. O diagnóstico é que a Constituição de 1988 determinou um aumento do gasto social que não acompanhava necessariamente o crescimento econômico e, até, podia prejudicá-lo ao alocar recursos para o consumo. 
A pressão por mais gasto público implicaria ampliação da carga tributária e/ou deficit público, que reduziriam a poupança diretamente (pelo aumento do consumo público) ou indiretamente, ao provocarem inflação.

A redução da poupança, por sua vez, produziria apreciação cambial real seja ao majorar a inflação doméstica, seja ao elevar a taxa de juros e, com isso, atrair poupança externa que apreciaria o câmbio nominal. Nesse sentido, a elevação de juros básicos pelo Banco Central apenas reagiria à pressão inflacionária inerente a uma intervenção pública que privilegiaria o consumo e deprimiria a poupança. A apreciação cambial, em seguida, prejudicaria atividades eficientes, reduzindo ainda mais a poupança.

Em suma, a interpretação neoliberal é que a desigualdade gera eficiência, e que a luta para a reduzir gera ineficiência, seja pela referida redução da poupança, seja pela diminuição dos 'incentivos' para a busca do lucro. Logo, a diminuição da participação do gasto social e do consumo dos assalariados na renda nacional, trazida pelas reformas neoliberais, aumentaria o próprio ritmo de crescimento da renda nacional e, em seguida, elevaria o valor absoluto do gasto social e da massa de salários. Na proposta, com a desvinculação dos gastos sociais assegurada pela Lei do Teto do Gasto, a reforma da previdência, o fim da política de valorização do salário mínimo e a reforma trabalhista, os lucros aumentariam e o emprego também, levando depois até a um aumento da massa de salários (embora aquém do ritmo de crescimento da renda nacional).

Essa interpretação não é sustentada empiricamente. Desde a década de 1980, a promessa do neoliberalismo era aumentar o crescimento econômico no mundo sob impacto da concentração da renda e da riqueza e de ampla integração econômica global. Tanto nos países desenvolvidos quanto nos subdesenvolvidos, a desigualdade aumentou como previsto, mas as taxas de crescimento caíram perceptivelmente em relação àquelas vigentes no pós-guerra, e mesmo em relação à década de 1970, em que a democracia estaria supostamente sufocando o capitalismo (CHANG, 2011; BASTOS, 2015).

No Brasil, o aumento do gasto social e da participação dos salários na renda correlacionou-se com uma ampliação do crescimento da renda agregada desde 2004, comparado seja com o período de avanço do neoliberalismo na década de 1990, seja com sua retomada desde 2015. O desemprego, em particular, caiu até 2014 enquanto os salários aumentaram, mas aumentou depois enquanto os salários reais caíram.

O salário mínimo real cresceu $70 \%$ entre 2004 e 2014, com impacto na escala de salários (dada a maior formalização) e nas pensões e aposentadorias. Além do seguro-desemprego, o conjunto de transferências sociais foi ampliado, notadamente o Bolsa Família, o Benefício de Prestação Continuada e o bônus salarial. A correlação de forças tornou-se favorável aos trabalhadores, levando a aumentos do salário real e dos direitos trabalhistas. A redução da desigualdade não prejudicou o crescimento, mas o estimulou.

Isso, aliás, está em linha com a experiência mundial: o aumento da desigualdade e da concentração da renda e da riqueza trouxe uma redução das taxas de crescimento e da duração das fases expansivas, como estudos do Fundo Monetário Internacional (FMI) mostraram cabalmente analisando vários países (OSTRY; LOOUNGANI; FURCERI, 2016; OSTRY; BERG; TSANGARIDES, 2014). Além disso, Peter Lindert (2004) fez um estudo histórico magistral para mostrar que, ao longo do tempo, o aumento do gasto social e das políticas redistributivas não custou nada em crescimento do Produto Interno Bruto (PIB), mas, ao contrário, pode ter acelerado seu crescimento. Quanto ao FMI, por partilhar de muitos dos esquemas teóricos dos autores neoclássicos e neoliberais que legitimam a desigualdade, seus estudos apenas refutam a hipótese neoliberal, mas não conseguem explicar porque ela não se verifica (BASTOS; BELLUZZO, 2016). 
O problema teórico central é que, para os neoclássicos, o que não é consumido, a poupança, se transforma direta ou indiretamente em investimento: quanto maior a poupança, maior o investimento, logo maior a produtividade do trabalho e a geração futura de riqueza e renda. Para John Maynard Keynes (1996), ao contrário, a poupança não se transforma necessariamente em gasto, pois a moeda (e seus equivalentes) pode ser entesourada de modo permanente. O gasto é que determina a renda, e não o contrário: $o$ investimento é determinado por expectativas futuras e é independente tanto da renda corrente quanto de uma decisão voluntária ou de imposição forçada de poupar parte da renda corrente. A renda corrente é que varia por causa das decisões autônomas de investimento, que podem ser financiadas, muito além da renda corrente, seja pelo estoque de riqueza acumulado (acrescido apenas na margem por um fluxo corrente de renda poupado), seja por criação de depósitos pelos bancos em nome dos que tomam empréstimos (BASTOS, 2017).

Exceto em uma situação raríssima em que todos os recursos existentes estejam plenamente ocupados, o aumento da demanda de bens de consumo aumenta também a demanda de trabalhadores, de insumos e de bens de capital para investimento. Ou seja, a demanda por 'fatores de produção' tende a seguir na mesma direção da demanda corrente que estimula a produção. À medida que a demanda corrente aumenta (diminui), o crescimento (redução) da produção ocupa (desocupa) a capacidade ociosa das empresas e incentiva (desincentiva) a realização de investimentos. Os neoclássicos, ao contrário, partem de um 'bolo' fixado em que uma fatia (o investimento) só poderia aumentar se outra (o consumo) diminuísse, mas não há qualquer base empírica para afirmar que a economia capitalista está sempre em situação de pleno emprego de recursos, muito antes pelo contrário. Sendo assim, uma redução da propensão a consumir (o aumento da propensão a poupar) não é uma pré-condição do aumento do investimento. Pelo contrário, tende a prejudicá-lo.

\section{Ativismo estatal e luta contra a desigualdade na época da globalização capitalista}

Um ponto central da crítica de Keynes (1996) aos autores neoclássicos sobre os impactos da distribuição de renda sobre o crescimento econômico foi sintetizado por Michal Kalecki (1987): como os trabalhadores tendem a gastar o que ganham, seus salários são itens de custo para alguns empresários, mas fonte de receita para outros. O que vale para uma empresa não vale para a macroeconomia.

Quando uma empresa paga menos salários, a demanda por bens e serviços vendidos por outros empresários diminui. Isso pode aumentar a capacidade ociosa das empresas e, portanto, diminuir a necessidade de investimentos. Quando os empresários investem menos, eles lucram menos como classe e podem ter problemas para pagar suas dívidas aos bancos.

É por isso que o que parece bom para o empresário egoísta não é necessariamente bom para os empresários como um todo. É também por isso que os economistas que defendiam a queda de salários para assegurar uma rápida recuperação em 2015 apenas mostravam seus parcos conhecimentos de economia e seus preconceitos sociais.

Como afirmamos, as políticas que deprimem a demanda de trabalhadores e do próprio Estado, em nome do aumento da 'poupança' capitalista (ou seja, dos lucros), não estimulam o investimento produtivo privado, mas o deprimem. Isso é um motivo fundamental porque o neoliberalismo e o aprofundamento da desigualdade que legitimou não trouxeram mais crescimento econômico, mas o contrário, e não só no Brasil, mas no mundo inteiro. 
De fato, o aumento da parcela da renda nacional apropriada pelos capitalistas não implicou aceleração dos investimentos em nova capacidade de oferta de bens e serviços, cuja taxa de crescimento caiu em relação à época do capitalismo das economias mistas. Mesmo nos EUA, com todas as inovações financeiras, o aumento enorme da alavancagem e a expansão do crédito a baixas taxas de juros a partir de 1990, a proporção do investimento no PIB caiu ao invés de crescer, de $20,5 \%$ nos anos 1980, para 18,7\% entre 1990 e 2009 (CHANG, 2011). Para onde foram os lucros?

Para responder a isso, é preciso entender o conceito de financeirização do capitalismo: a importância assumida pelos mercados financeiros para a dinâmica macroeconômica e para a estratégia microeconômica dos grupos conglomerados e grandes investidores (institucionais e individuais). Os mercados financeiros são menos importantes hoje em seu papel primário (alocar recursos para novos investimentos produtivos) do que nos mercados secundários (transacionar direitos sobre a riqueza já existente). Os autores neoclássicos que supõem que o aumento da 'poupança', ou melhor, da parcela dos lucros na renda agregada trará necessariamente investimentos produtivos não ignoram apenas os problemas teóricos básicos associados ao conceito de poupança que foram apontados por Keynes (1996) e Kalecki (1987). Eles também não têm a menor noção das transformações institucionais da forma de organização da riqueza capitalista e dos mercados financeiros nas últimas décadas'

Além da mania de fusões e aquisições de riqueza já existente (contando com mais da metade do investimento direto externo desde 1990) e do entesouramento em títulos da dívida pública, a expansão dos lucros inflou a especulação com ativos comprados com a expectativa de revenda a preços superiores, sem trazer sequer um aumento na taxa de crescimento do investimento produtivo, para não falar da proporção do investimento produtivo no PIB. Macroeconomicamente, o crescimento do setor financeiro foi muito maior do que a economia 'subjacente', um indicador de que o aumento da 'poupança' não foi canalizado para novos investimentos produtivos. $\mathrm{O}$ estoque de ativos financeiros em relação à produção mundial cresceu de $120 \%$ para $440 \%$ entre 1980 e 2007, chegando a $700 \%$ para economias muito financeirizadas como a Grã-Bretanha (PALMA, 2009). Nos EUA, flutuava entre 400-500\% entre 19501980, e alcançou $900 \%$ no início dos anos 2000 (CROTTY, 2007).

Exceto poucos países minúsculos ou com grande riqueza mineral, os casos que puxam para cima a média da taxa de crescimento global na época neoliberal preservaram papel ativo do Estado na mudança produtiva e na inserção global, independentemente da postura em relação à desigualdade social. De fato, os maiores avanços ocorreram enquanto os Estados controlaram o ritmo e o escopo da liberalização e da financeirização, e onde influenciaram o investimento industrial e em infraestrutura, regularam fluxos de capitais, mantiveram grandes empresas e bancos públicos, juros baixos e câmbio competitivo para as empresas privadas (como no leste asiático e notadamente na Índia e na China). No Brasil, a globalização ampliou o desemprego.

Foram, em parte, o desemprego e o desencanto com as promessas da globalização neoliberal que levaram à vitória de Luís Inácio Lula da Silva em 2002. Foram os compromissos históricos do Partido dos Trabalhadores (PT) e a pressão dos sindicatos (em particular, da principal central sindical, a Central Única dos Trabalhadores - CUT) que criaram a correlação de forças favorável à política de elevação do salário mínimo real e à maior fiscalização do Ministério do Trabalho para a formalização do emprego. Foi também proposta sindical a redução de juros para os trabalhadores via crédito consignado (em que parcelas da dívida são descontadas da folha salarial). Tudo isso provocou o inverso do que as reformas neoliberais e a globalização
1 Para a breve discussão

da financeirização que se segue e seu aprofundamento, ver Bastos (2015). 
2 Para uma crítica teórica devastadora sobre o conceito de capital humano, ver Bowles e Gintis (1975); para questionamentos da experiência histórica, ver Pritchett (2001), Wolf (2002) e Chang (2011) assimétrica provocavam no mundo inteiro: a ampliação da participação dos assalariados na renda nacional.

É importante entender que, assim como a queda do custo do trabalho não trouxe mais crescimento na década de 1990, o aumento dos salários diretos e indiretos teve forte impacto sobre o perfil distributivo e nítido efeito positivo sobre a taxa e o estilo de crescimento. A ampliação da participação dos assalariados na renda nacional levou à grande ampliação do mercado consumidor de bens duráveis, serviços e imóveis. Isso aumentou a renda nacional, os lucros e os investimentos capitalistas, em processo explicado teoricamente por Keynes (1996) e Kalecki (1987), e incompreendido pelos neoclássicos. No longo ciclo de crescimento iniciado em 2004, o investimento e o consumo privado reagiram, primeiro, à expansão das exportações determinada pela recuperação mundial e, em seguida, acompanharam a massa salarial, as transferências sociais, o crédito consignado e os programas de infraestrutura. No período, a redução da capacidade ociosa e as perspectivas de crescimento do mercado interno fizeram com que o investimento crescesse a taxas maiores que as do consumo, de modo que uma coisa não exclui a outra (CARNEIRO, 2010; BIELSCHOWSKY ET AL., 2014).

É preciso reconhecer que, especialmente depois de 2008 , as políticas industriais, comerciais e cambiais (mesmo porque eram contraditórias entre si) não foram suficientes para que o estímulo do crescimento do mercado interno se traduzisse em diversificação e ganho de complexidade dos investimentos no setor industrial e de serviços. Isso ajuda a explicar a desaceleração até 2014, embora a depressão em 2015 seja de responsabilidade das políticas neoliberais executadas a partir daí.

De todo modo, a experiência brasileira entre 2004 e 2014 mostra que as políticas industriais, comerciais e cambiais são essenciais para o dinamismo no padrão de concorrência contemporâneo, mas que outras formas de política estatal também são importantes não apenas para o dinamismo econômico, mas para sua qualidade. $\mathrm{O}$ gasto social e a redução da desigualdade, em particular, trazem pelo menos cinco tipos de estímulo para o crescimento econômico que influenciam também sua qualidade. Primeiro, asseguram maior coesão social e conferem mais incentivos para o trabalho e a cooperação social, mesmo quando não focam diretamente em trabalhadores ativos, mas em crianças e idosos de suas famílias. Ou seja, sem esquecer que a solidariedade social é um fim em si, ela também estimula o crescimento econômico (STIGLITZ, 2012). Segundo, oferecem aos trabalhadores e pequenos empresários uma rede de proteção que diminui o custo de arriscar e inovar (CHANG, 2011). Terceiro, protegem a saúde, melhoram habitações e qualificam educacionalmente os trabalhadores, o que os próprios neoclássicos chamam (erroneamente) de um 'capital humano' favorável ao crescimento $^{2}$.

Quarto, a redução da heterogeneidade social e regional na oferta de infraestrutura e serviços públicos gera demanda que canaliza o crescimento do mercado interno para indução e diversificação de investimentos privados, oferecendo também externalidades que possibilitam novos investimentos e aumentam a competividade de empresas privadas (HIRSCHMAN, 1961; MYRDAL, 1972).

Finalmente, a redistribuição da renda por meio da taxação de proprietários da riqueza e de indivíduos de alta renda, para financiar transferências monetárias para aliviar a pobreza e serviços sociais para cidadãos incapazes de pagar serviços privados, expande a renda agregada mesmo quando o orçamento público é equilibrado. Isso foi demonstrado por Trygve Haavelmo (1945) tendo por base a diferença entre a propensão a consumir entre os cidadãos taxados - cuja renda tributada não seria inteiramente gasta (nem em consumo, nem em investimento produtivo, pois em parte entesourada) - e a propensão a consumir dos cidadãos cuja renda disponível 
aumenta por efeito do gasto público. $\mathrm{O}$ importante é assegurar o efeito distributivo da arrecadação tributária e do gasto público que ela financia: se taxar aqueles que consomem uma proporção menor de sua renda e gastar apenas o que taxa, o governo já terá aumentado a demanda agregada. Se, ainda por cima, estimular a renda dos cidadãos mais pobres (que consomem proporcionalmente mais de sua renda), o governo não só favorece a coesão social, mas estimula ainda mais o crescimento econômico. Assim, mesmo o gasto público não deficitário tem um efeito multiplicador favorável ao crescimento da demanda agregada que, em seguida, pode ter um efeito-acelerador sobre o investimento privado à medida que a capacidade ociosa diminui.

No caso brasileiro, pesquisadores do Instituto de Pesquisa Econômica Aplicada (Ipea) usaram técnicas econométricas avançadas para estimar o multiplicador do gasto público. A conclusão é que o gasto social tem um grande poder de estimular a renda nacional e, portanto, a própria arrecadação tributária futura. O gasto social é um investimento no Brasil e no seu povo que não tem custo econômico ao longo do tempo, mas sim benefícios econômicos quantitativos, para não mencionar a melhoria da qualidade do crescimento ${ }^{3}$.

Ao contrário, a proposta neoliberal materializada na Lei do Teto do Gasto, que corta o gasto social per capita em termos reais para priorizar o pagamento de uma dívida pública rolada a taxas de juros estratosféricas, concentra a renda para portadores da riqueza financeira esterilizada em títulos públicos e é um desestímulo ao crescimento econômico. Os juros da dívida pública são o item de gasto público com o menor efeito multiplicador, estimado em apenas 0,71 .

Por tudo isso, as reformas neoliberais implementadas pelo governo Temer não vão apenas tornar o País mais desigual, mas também limitar o crescimento econômico e a geração de empregos. É para evitar tamanha destruição e canalizar construtivamente a reação da sociedade brasileira que precisamos pensar os elementos de um novo programa nacional. No que se segue, seu delineamento básico é apresentado de forma bastante sintética.

\section{As bases de um projeto nacional}

As bases de um projeto nacional passam por debater políticas emergenciais que evitem o aprofundamento e assegurem a superação da crise. É preciso também retomar o legado paralisado de programas que atendiam importantes demandas sociais e têm grande efeito multiplicador, assim como imaginar novos projetos com as mesmas características. Finalmente, é fundamental delinear os princípios e imaginar meios de financiar o programa com justiça fiscal.

\section{Renegociação e alongamento de dívidas}

A saída da crise depende de certas políticas emergenciais. Como as empresas estão endividadas e com capacidade ociosa, a recuperação não tende a partir do investimento privado e da expansão do crédito. Logo, mecanismos de crédito precisam basicamente renegociar e alongar o pagamento das dívidas. Um pool de bancos públicos deve ser mobilizado e atrair bancos privados para avaliar e alongar dívidas conjuntamente (tecnicamente, fazer 'empréstimos sindicalizados').

A 'renegociação das dívidas', sobretudo de empreiteiras e construtoras, é de alta prioridade, porque sua falência implicará novas quebras de fornecedores menores, aumento do desemprego e desnacionalização. Isso passa por acelerar acordos de leniência e reverter o caráter antinacional da Lava Jato.

Como as famílias também estão endividadas, a ação conjunta dos bancos públicos também é necessária para reduzir juros e

\footnotetext{
3 As estimativas para o multiplicador, ou seja, para a variação da renda agregada gerada por uma unidade monetária de dispêndio público autônomo, foram as seguintes: educação, 1,85; saúde, 1,7; Bolsa Família, 1,44; Benefício de Prestação Continuada, 1,38; Regime Geral de Previdência Social, 1,2. Em comparação, o Regime Público de Previdência Social tem multiplicador de apenas 0,88, em razão da existência de aposentadorias acima do teto legal de remuneração do funcionalismo público. Ver Ipea $(2010,2011)$ Castro (2012a, 2012b). Para novas estimativas que vão no mesmo sentido, ver Orair, Siqueira e Gobetti (2016).
} 
facilitar 'renegociação de dívidas de consumidores'. Além disso, é fundamental 'alongar a vigência do seguro-desemprego', desde junho de 2015, limitado a quatro ou cinco parcelas na primeira solicitação; mais quatro na segunda e mais três na terceira. O desemprego de longo prazo, porém, já se instalou no País, e não podemos produzir mendigos ou algo pior por falta de opção.

Enfim, a 'renegociação da dívida com estados e municípios' é fundamental. É preciso garantir gastos correntes e conclusão de obras paralisadas, barrando a imposição da emenda constitucional do teto de gastos federais e sua imposição nos contratos com estados.

\section{A retomada do legado paralisado e 0 debate de novos projetos}

Como a maturação de novos projetos (e bandeiras) de longo prazo é lenta (por motivos de engenharia técnica, financeira e ambiental), eles podem ser planejados enquanto são reativados vários programas desativados por Temer. Como afirmado, a estratégia política do governo Temer era paralisar o legado institucional e programático construído a partir da Constituição de 1988 e retomado no governo Lula. Se a economia se recuperasse, o povo esqueceria esse legado, que não poderia ser usado como trunfo nas eleições de 2018.

Como a recuperação não veio, a nostalgia da população perante o legado do lulismo aumentou. A própria paralisia deliberada de programas que tinham grande efeito multiplicador tem uma boa responsabilidade pelo prolongamento da recessão, e sua reativação não apenas atenderá a uma demanda popular, como também é mecanismo seguro para acelerar a recuperação. Cito aqui, sobretudo, oito legados:

1) Política de 'encomendas públicas com conteúdo tecnológico local', inclusive na Petrobrás;
2) Retomada 'de obras de grande impacto' (transposição do São Francisco com projetos de irrigação, conclusão das ferrovias) e em grandes cidades (principalmente mobilidade urbana);

3) 'Minha Casa, Minha Vida', vinculado com urbanização de favelas, ocupações e loteamentos ilegais e programa de substituição energética;

4) Apoio 'federal à Atenção Primária à Saúde, Unidades Básicas de Saúde (UBSs), Farmácia Popular e Mais Médicos';

5) Expansão de 'Institutos Federais de Ensino e do Pronatec (Programa Nacional de Acesso ao Ensino Técnico e Emprego), depois campus' universitários;

6) ‘Elevação de salário mínimo’;

7) Ampliação do 'Bolsa Família e da linha de pobreza', inclusive com $13^{\circ}$ salário;

8) Fortalecimento 'da agricultura familiar', com apoio à reforma agrária e formação de cooperativas.

O princípio central é reverter a marginalização social e, ao universalizar infraestrutura e serviços públicos, canalizar o crescimento do mercado interno para indução e diversificação de investimentos privados. Que novos projetos e bandeiras, no mesmo sentido, podem ser planejados?

1) O programa Saneamento para Todos deve ser transformado em prioridade nacional, eventualmente convertido no programa Água para Todos para marcar a prioridade e articulá-lo ao reaproveitamento;

2) Emprego Para Todos: ter o pleno emprego como meta e oferecer seguro-desemprego para todos que precisem até $o$ alcance da meta; 
3) Banda Larga para Todos: universalizar o acesso à internet e democratizar a produção de conteúdo;

4) Luz do Sol Para Todos: universalizar placas solares e usinas eólicas, começando com 'programa-piloto no Semiárido', depois em 'hospitais, escolas e universidades'; a seguir estendendo 'para favelas e loteamentos ilegais', substituindo 'gatos', de modo que ninguém perca, todos ganhem.

Os investimentos públicos no setor de petróleo e gás, na saúde, na mobilidade urbana, na banda larga e nas novas formas de energia devem estar vinculados à indução de investimentos privados e ao ganho de capacitação tecnológica local. Isso aumentaria a complexidade, os encadeamentos e os estímulos recíprocos dos investimentos na economia brasileira, recuperando parte da diversidade perdida ao longo das décadas de neoliberalismo. Isso pode inclusive desenvolver capacitações necessárias para um aumento posterior das exportações, tendo por base um mercado interno dinâmico e sendo apoiadas por políticas comerciais e cambiais apropriadas.

Não obstante a importância do aumento da complexidade da economia envolvida nestes ramos, é importante considerar que a heterogeneidade (social, regional e urbana) brasileira é tamanha que o combate a ela também é base de um programa reformista com capacidade de sustentação política e dinamismo econômico.

Dada a heterogeneidade estrutural característica do Brasil, a extensão das infraestruturas tradicionais, com tecnologias já dominadas, traz enorme potencial de crescimento econômico. O fundamental é ter políticas comerciais, industriais e cambiais para assegurar que os incentivos gerados pela expansão do mercado interno, seja pela redução da heterogeneidade, seja pelo ganho de complexidade, sejam capturados internamente, estimulando a diversificação, ampliando o potencial de crescimento e de combate às desigualdades (BASTOS, 2012).
Não se trata apenas de substituir importações já estimuladas por razões de competitividade-preço (relação salário/câmbio e tarifas) e falta de capacitação produtiva local, mas de criar novas demandas e encadeamentos setoriais que não sejam capturadas pelas importações futuras. Trata-se, em suma, de proteger a capacidade de diversificação ulterior da economia brasileira e seu mercado interno para que atenda suas novas demandas sem que as importações sejam determinadas por um câmbio apreciado ou por carência de capacitações ao alcance do potencial do sistema produtivo e tecnológico brasileiro, mas pelas complementariedades do comércio exterior estimuladoras do desenvolvimento nacional.

\section{Como financiar?}

O princípio básico é que não é preciso cortar direitos para financiar o investimento público. A rejeição das reformas golpistas (Previdência, Trabalhista, Teto do Gasto) deve ser feita lembrando o tamanho da 'sonegação anual ( $\mathrm{R} \$ 500$ bilhões), dívida ativa da União ( $\mathrm{R}$ \$ 1,8 trilhão), dívida ativa de cobrança imediata ( $\mathrm{R} \$ 260$ bilhões) e dívida com a Previdência Social (R $\$ 426$ bilhões)'. No entanto, fazer cumprir a lei tributária também exige cumprir 'a Lei do Teto do salário do funcionalismo público', objeto de várias distorções que o corrompem 4 .

Além de um força-tarefa para 'combate à sonegação e cobrança da dívida ativa', há três Iniciativas tributárias e financeiras 'emergenciais' que podem ser propostas:

1) 'CPMF' de início com alíquota de 0,01\% ou, se houver resistência, no limite até 0,001\% (para atacar a sonegação: quem dirá não?);

2) Acelerar 'liberação do FGTS' para obras em saneamento, e reforçá-las com bancos públicos e, se quiserem, privados, iniciando o Água Para Todos;
4 Ver em especial os estudos do Sinprofaz (2017) e do Inesc (2016). 
3) Usar parte das reservas cambiais para constituição de um 'Fundo Social de Desenvolvimento', e outra parte como garantia para empréstimos de longo prazo com o Banco dos Brics, estimulando a concorrência do Banco Interamericano de Desenvolvimento (BID) e do Banco Mundial.

O princípio básico é que se deve financiar o desenvolvimento 'com progressividade tributária'. Conforme delineado no documento 'Austeridade e retrocesso', cabe iniciar com a cobrança imediata (no ano seguinte à aprovação legal) do imposto sobre lucros e dividendos distribuídos das empresas para as pessoas físicas e, dois anos depois, fim da dedução de juros sobre capital próprio.

É possível 'trocar o aumento da progressividade de impostos diretos' (imposto de renda, herança, rural, fortunas) e eliminação de isenções regressivas (contribuições sociais; saúde; subsídios empresariais) por aumento da faixa de isenção do imposto de renda e unificação/redução de alíquota de impostos em cascata.

Além disso, é possível recorrer à cooperação internacional. Por exemplo, por que não propor um 'fundo ambiental internacional' para apoiar o Luz do Sol Para
Todos (Sunshine for All), com programas-pilotos para placas solares e usinas eólicas no Semiárido do Brasil e na África? No Brasil, o objetivo inicial seria apoiar a irrigação e a agricultura familiar no Semiárido, reduzir a Conta de Desenvolvimento Energético e a conta de luz de repartições públicas, além de estimular um novo ramo de atividade verde e tecnologicamente avançado. Para esta e outras iniciativas, o potencial de financiamento do sistema brasileiro de bancos públicos deve ser mobilizado com inteligência e seletividade.

Essas são algumas ideias que precisamos aprofundar para retomar a esperança no futuro e assegurar o desenvolvimento de um Brasil para todos. 'Assim como devemos pensar grande nas finalidades, a ação também deve priorizar a Grande Política, inspirando grandes massas'. Não adianta se autolimitar, evitando políticas que desagradem parcelas ideologizadas e radicais da classe média e do empresariado; parte delas só será ganha politicamente com a retomada do crescimento, uma boa parte nem com isso. É importante que esbarremos em limites externos, e não em limites autoimpostos. A busca da unanimidade paralisa. Lutemos por um Brasil para todos, mas de baixo para cima. 


\section{Referências}

BASTOS, P. A economia política do novo-desenvolvimentismo e do social desenvolvimentismo. Economia e sociedade, Campinas, v. 21, n. 4, dez. 2012.

Austeridade permanente? A crise global do capitalismo neoliberal e as alternativas no Brasil. Texto para Discussão, Campinas, n. 257, ago. 2015.

Macroeconomia e mercado de trabalho: as principais teorias e o Brasil contemporâneo. Revista Ciências do Trabalho, São Paulo, n. 7, p. 51-107, abr. 2017.

BASTOS, P. P. Z.; BELLUZZO, L. G. Uma crítica aos pressupostos do ajuste econômico. Folha digital, São Paulo, 9 out. 2016.

BIELSCHOWSKY, R.; SQUEFF, G.; VASCONCELLOS, L. Evolução dos investimentos nas três frentes de expansão da economia brasileira na década de 2000. In: CALIXTRE, A. B.; BIANCARELLI, A. M.; CINTRA, M. A. M. (Ed.). Presente e futuro do desenvolvimento brasileiro. Brasília, DF: Ipea, 2014. p. 135-194.

BOWLES, S.; GINTIS, H. The problem with human capital theory: a Marxian critique. The American Economic Review, Pittsburgo, v. 65, n. 2, p. 74-82, 1975.

CARNEIRO, R. O desenvolvimento brasileiro pós-crise financeira: oportunidades e riscos. Observatório da Economia Global, Campinas, n. 4, ago. 2010. Disponível em: <http://www3.eco.unicamp.br/cecon/images/arquivos/observatorio/Desenvolvimento_poscrise.pdf $>$. Acesso em: 28 jun. 2017.

CASTRO, J. A. Política social e desenvolvimento no Brasil. Economia e Sociedade, Campinas, v. 21, n. esp. dez. 2012a.

Saúde e desenvolvimento. 2012b.

Mimeografado.

CHANG, H. J. 23 things they don't tell you about capitalism. 2. ed. Nova Iorque: Bloomsbury, 2011.
CROTTY, J. If financial market competition is so intense, why are financial firm profits so high? Reflection on the current golden age of finance. Amherst: University of Massachusetts Amherst, 2007.

HAAVELMO, T. Multiplier effects of a balanced budget. Econometrica: Journal of the Econometric Society, [S.l.], v. 13, n. 4, p. 311-318, out. 1945.

HIRSCHMAN, A. Estratégia do desenvolvimento econômico. Rio de Janeiro: Fundo de Cultura, 1961.

INSTITUTO DE ESTUDOS SOCIOECONÔMICOS (INESC). Nossos direitos cabem no orçamento: sonegação, privilégios e desigualdade fiscal é que não cabem. 2016. Disponível em: <http://www.inesc.org. $\mathrm{br} /$ noticias/noticias-do-inesc/2016/outubro/nossos-direitos-cabem-no-orcamento-o-que-nao-cabem-e-sonegacao-privilegios-e-desigualdade-fiscal>. Acesso em: 12 maio 2017.

\section{INSTITUTO DE PESQUISA ECONÔMICA}

APLICADA (IPEA). Efeitos econômicos do gasto social no Brasil. Brasília, DF: Ipea, 2010.

Gastos com a Política Social: alavanca para o crescimento com distribuição de renda. Comunicados do Ipea, n. 75, Brasília, DF, 2011. Disponível em: $<$ http://www.ipea.gov.br/agencia/images/stories/ PDFs/comunicado/110203_comunicadoipea75_apresentacao.pdf > . Acesso em: 12 maio 2017.

KALECKI, M. Salários nominais e reais. In: MIGLIOLI, J. (Org.). Crescimento e ciclo das economias capitalistas. 2. ed. São Paulo: Hucitec, 1987.

KEYNES, J. M. A teoria geral do emprego, do juro e da moeda. São Paulo: Nova Cultural, 1996.

LINDERT, P. H. Growing Public. Cambridge:

Cambridge University Press, 2004. v. 1.

MYRDAL, G. Teoria econômica e regiões subdesenvolvidas. Rio de Janeiro: Saga, 1972. 
ORAIR, R.; SIQUEIRA, F. F.; GOBETTI, S. W. Política

Fiscal e Ciclo Econômico: uma análise baseada em multiplicadores do gasto público. Brasília, DF: Tesouro Nacional, 2016

OSTRY, D. J.; BERG, A.; TSANGARIDES, C. G. Redistribution, Inequality, and Growth. Washington: International Monetary Fund, 2014.

OSTRY, D. J.; LOOUNGANI, P.; FURCERI, D. Neoliberalism Oversold. IMF: Finance \& Development, [s.l.], v. 53, n. 2, jun. 2016. Disponível em: <https://www. imf.org/external/pubs/ft/fandd/2016/06/pdf/ostry. pdf>. Acesso em: 12 maio 2017.

PALMA, G. The revenge of the market on the rentiers. Cambridge Journal of Economics, Cambridge, v. 33, n. 4, jul. 2009.
PRITCHETT, L. Where has all the education gone. The world bank, Washington, v. 15, n. 3, p. 367-391, 2001.

SINDICATO NACIONAL DOS PROCURADORES DA

FAZENDA (SINPROFAZ). Sonegação no Brasil: uma estimativa do desvio da arrecadação do exercício de 2016. Brasília, DF: Sinprofaz, 2017.

STIGLITZ, J. E. The price of inequality: how today's divided society endangers our future. Londres: Norton \& Company, 2012.

WOLF, A. Does education matter: myths about education and economic growth. Londres: Penguin, 2002. 